\title{
Construct A New Pattern of Industrial Development-Take Hunan as an Example
}

\author{
Naman Yang ${ }^{1,2}$ \\ ${ }^{1}$ Institute of industrial Economics, Chinese Academy of Social Sciences, Beijing 100836, China \\ ${ }^{2}$ Party School of the Organs Directly Under the Hunan Provincial Committee of C.P.C, Changsha, \\ 410001, China
}

Keywords: Industrial development, Steepest descent, Hunan

\begin{abstract}
There is a relative lack of systematic and empirical research on the industrial development based on the macro perspective in the domestic academic field. Aimed at this shortcoming, Hunan is selected as the research target to attempt to solve the problem of steepest front in industrial development. To solve this problem, a basic investigation was conducted to obtain the basic data required for the system research. Then agglomeration degree model was used to transform the basic data into agglomeration degree data and the corresponding macro analysis was made. In combination with the enlightenment from the macro analysis, the factors with significant relevance wee determined from the perspective of correlation analysis, and then the metering model of industrial development in Hunan was constructed by relying on these factors. Finally, in combination with the previous analysis result, the steepest model was constructed for the industrial development of Hunan and the solution was successfully calculated to obtain the steepest direction of industrial development in Hunan, and the suggestions to construct a new pattern of industrial development in Hunan were proposed.
\end{abstract}

\section{Introduction}

Hunan is a large province in central South China, and its macro economy and industrial development have been standstill in recent years, with a trend of increasing development gap with the adjacent provinces. Aimed at this actual dilemma, we attempt to find out a method to solve this problem by combining the theory of subjects such as regional economy, macro economy, micro economy, mathematical analysis with the methods. The research with the method above is completely obtained on the basis of reviewing the research achievements of domestic and foreign scholars in this field. Then, in the analysis on economy of Hunan and the main industrial agglomeration, we obtain the basic data for the research through basic survey, and by starting from the agglomeration degree, we have an overall analysis on the development of Hunan economy and main industries. In the following, in the correlation statistical verification of economic output and main industrial development indicators of Hunan, from the perspective of correlation, we make a correlation analysis on 15 key indicators potential in the development of macro economy of Hunan, and determine 10 key factors with significant correlation. On this basis, in the analysis on the steepest development of main industry in Hunan, we carry out metering research and steepest development direction research on main industries in Hunan, and finally determine the steepest front of economic and industrial development in Hunan through quantification, and obtain the steepest direction of industrial development in Hunan, and on the basis of summarizing the whole paper, we propose the suggestion to construct a new pattern of industrial development in Hunan. Next, we will research the corresponding part based on this sequence.

\section{Review of domestic research results}

The foreign scholars Anna Trevisan, Massimo D'Isidoro and Olivier Talagrand (2010) ${ }^{\mathrm{i}}$ had a deep research on VAR analysis, and proposed 4-D VAR analysis method, conducted theoretical analysis and simulation verification on its applicability and advantages and disadvantages, so as to verify its specific advantages in applicability. Domestic scholar Jin Yuguo (2012) ii, starting from the 
perspective of theoretical analysis, specifically researched on the research method of econometric analysis. He had a full survey on the development process of latent variable model in the econometrics from the perspective of methodology, compared the characteristics of modeling methods in various stages, summarized its development and evolution law and prospected the key areas in the next research. The Chinese scholar Zhang Yanqun (2012) ${ }^{\text {iii }}$, based on the GVAR model, had an analysis and research, and he empirically analyzed the mutual influence of the Chinese economy and world economy. Through the general shock response function method, he analyzed the transmission mechanism, influence strength and duration of the Chinese demand shock, American demand shock, American bond market price and international oil price change etc. to the economic growth and inflation of other countries. The result showed that the Chinese demand shock has a significant influence on the main industrialized countries like America, Euro region and Japan, and the Chinese economy is also strongly shocked by the change of American bond price. The domestic scholars Pan Kangyu, Zhao Ying and Li Lijun (2012) ${ }^{\text {iv }}$ carried out an empirical analysis on the correlation of talent agglomeration and economic development in the development of regional economy, with Tianjin Binhai New Town as an example. Through the basis survey, the basic data for the research are obtained through basic survey, and in combination with this data structure, the metering model between the talent agglomeration and economic development of Tianjin Binhai New Town is constructed ${ }^{\mathrm{v}}$. Through the deep analysis on this model it is found that the talent agglomeration in Binhai New Town has stepped from the coordination stage to the mutation stage. In combination with this analysis result, specific countermeasures and suggestions are proposed for the rapid and stable development of Binhai New Town from the perspectives of human resources development utilization and management.

\section{Analysis on agglomeration degree of economy and main industries in Hunan}

In this section, we will have an overall analysis on the agglomeration degree of economy and main industries in Hunan. Unlike the previous researches, the overall analysis (or macro analysis) is to research from the perspective of regional development. In order to ensure the comprehension of the research as far as possible, by referring to the statistical yearbook and professional economic database, we have obtained the main economic development indicators of Hunan, mainly including the following 15 data: regional GDP (current price), added value of primary industry in various regions, added value of secondary industry in various regions, industrial added value in various regions, added value of building industry, added value of tertiary industry in various regions, added value of transportation and post communication industry in various regions, added value of wholesales and retains, trade and catering industry in various regions, total amount of fixed capital, total investment of fixed assets in the whole society, total import and export, total export, actual use of foreign capital in direct foreign direct investment, international tourism income and number of practitioners at the end of the year ${ }^{\mathrm{vi}}$.

\section{Statistical verification of correlation of economic output and main industrial development indicators in Hunan}

Before constructing the econometric model, we analyze whether there exists correlation between the variables to be researched first. For the correlation research, there are three famous research methods, respectively Pearson correlation analysis, Spearman correlation analysis and Kendall correlation analysis. Here we use the most famous Pearson correlation analysis for the corresponding research, and the mathematical expression corresponding to this analysis method is as follows (see formula 2): 


$$
\text { Re lation }_{\text {pierson }}=\frac{\sum_{i=1}^{w}\left(x_{i}-\bar{x}\right)\left(y_{i}-\bar{y}\right)}{\sqrt{\sum_{i=1}^{w}\left(x_{i}-\bar{x}\right)^{2}} \sqrt{\sum_{i=1}^{w}\left(y_{i}-\bar{y}\right)^{2}}}
$$

Note: variables $x_{i}$ and $y_{i}$ represent the $i$ th pair elements of the data sequence for which correlation is required to be determined, variables $\bar{x}$ and $\bar{y}$ represent the average values of $x_{i}$ and $y_{i}$, variable $w$ represents the total pair of the data, and variable Re lation $_{\text {pierson }}$ represents the Pearson correlation coefficient.

Using the above Pearson correlation analysis and in combination with the 15 agglomeration degree data displayed in Table 1 and Table 2, we can get the correlation between all items. This research stresses the analysis where exists correlation between the regional GDP agglomeration degree and other 14 agglomeration degrees, and if yes, what's the specific form? Therefore, here we only analyze the correlation between the regional GDP agglomeration degree and other 14 agglomeration degrees. The correlation analysis result is summarized as follows (see Table 3).

Table1. Result of correlation verification of economic output and main industrial development in Hunan

\begin{tabular}{|c|c|c|c|c|c|c|c|c|c|c|}
\hline $\begin{array}{c}\text { Pearson } \\
\text { correlatio } \\
n\end{array}$ & $\begin{array}{l}\text { Regional } \\
\text { GDP } \\
\text { agglomer } \\
\text { ation } \\
\text { degree }\end{array}$ & $\begin{array}{l}\text { Agglome } \\
\text { ration } \\
\text { degree of } \\
\text { added } \\
\text { value of } \\
\text { primary } \\
\text { industry }\end{array}$ & \multicolumn{2}{|c|}{$\begin{array}{l}\text { Agglome } \\
\text { ration } \\
\text { degree of } \\
\text { added } \\
\text { value of } \\
\text { secondar } \\
\text { y industry }\end{array}$} & \multicolumn{2}{|c|}{$\begin{array}{l}\text { Agglome } \\
\text { ration } \\
\text { degree } \\
\text { industrial } \\
\text { added } \\
\text { value }\end{array}$} & $\begin{array}{l}\text { Agglome } \\
\text { ration } \\
\text { degree of } \\
\text { added } \\
\text { value } \\
\text { building } \\
\text { industry }\end{array}$ & $\begin{array}{l}\text { Agglome } \\
\text { ration } \\
\text { degree of } \\
\text { added } \\
\text { value of } \\
\text { tertiary } \\
\text { industry }\end{array}$ & $\begin{array}{l}\text { Agglomer } \\
\text { ation } \\
\text { degree of } \\
\text { added } \\
\text { value of } \\
\text { transporta } \\
\text { tion and } \\
\text { post } \\
\text { communi } \\
\text { cation } \\
\text { industry }\end{array}$ & $\begin{array}{l}\text { Agglome } \\
\text { ration } \\
\text { degree of } \\
\text { added } \\
\text { value of } \\
\text { wholesale } \\
\text { s and } \\
\text { retails } \\
\text { trade and } \\
\text { catering } \\
\text { industry } \\
\end{array}$ \\
\hline $\begin{array}{l}\text { Regional } \\
\text { GDP } \\
\text { agglomer } \\
\text { ation } \\
\text { degree } \\
\end{array}$ & 1 & 0.9933 & & 087 & 0.97 & & -0.96 & 0.9565 & 0.7917 & 0.7611 \\
\hline $\begin{array}{l}\text { Pearson } \\
\text { correlation } \\
\text { coefficient }\end{array}$ & $\begin{array}{l}\text { Agglomera } \\
\text { tion degree } \\
\text { of total } \\
\text { amount of } \\
\text { fixed asset }\end{array}$ & $\begin{array}{r}\text { Agglo } \\
\text { tion d } \\
\text { of tc } \\
\text { fixed } \\
\text { invest } \\
\text { in } t \\
\text { wh } \\
\text { soci }\end{array}$ & $\begin{array}{l}\text { hera } \\
\text { gree } \\
\text { al } \\
\text { sset } \\
\text { hent } \\
\text { e } \\
\text { e } \\
\text { ty }\end{array}$ & $\begin{array}{r}\text { Agglo } \\
\text { tion d } \\
\text { of tc } \\
\text { impor } \\
\text { exp }\end{array}$ & $\begin{array}{l}\text { mera } \\
\text { egree } \\
\text { otal } \\
\text { t and } \\
\text { ort }\end{array}$ & & $\begin{array}{l}\text { lomera } \\
\text { degree } \\
\text { total } \\
\text { port }\end{array}$ & $\begin{array}{c}\text { Agglomera } \\
\text { tion degree } \\
\text { of actual } \\
\text { foreign } \\
\text { capital use } \\
\text { of foreign } \\
\text { direct } \\
\text { investment }\end{array}$ & $\begin{array}{l}\text { Agglomera } \\
\text { tion degree } \\
\text { of } \\
\text { internation } \\
\text { al tourism } \\
\text { income }\end{array}$ & $\begin{array}{c}\text { Agglomera } \\
\text { tion degree } \\
\text { of number } \\
\text { of } \\
\text { practitione } \\
\text { rs at the } \\
\text { end of the } \\
\text { year }\end{array}$ \\
\hline $\begin{array}{c}\text { Regional } \\
\text { GDP } \\
\text { agglomera } \\
\text { tion } \\
\text { degree }\end{array}$ & -0.9799 & -0.9 & & 0.32 & 223 & & 9691 & -0.9632 & -0.9589 & 0.967 \\
\hline
\end{tabular}

According to the theoretical requirements of statistics, the confidence coefficient with absolute value below 0.95 is generally not accepted. Based on this standard and in combination with the analysis result in Table 3, we can confirm that there is no correlation between the regional GDP agglomeration degree in Hunan and the agglomeration degrees of added value of the secondary industry, added value of transportation and post communication industry, added value of wholesales 
and retains, trade and catering industry, total import and export; and there exists a significant correlation between regional GDP agglomeration degree in Hunan and other agglomeration degrees except those above.

Next, we will use the regional GDP agglomeration degree in Hunan and the factors with correlation with it for econometric analysis, so as to determine the metering model of economic development in Hunan, and take it as the last difficulty to overcome in this research.

\section{Analysis on steepest development direction of main industries in Hunan}

In the previous section, we have determined the factors with a significant correlation with the economic agglomeration degree in Hunan, next, we will use the method of econometric analysis research to construct an econometric model for these researches. The whole econometric analysis is completed with econometric analysis software EViews6.5, and the econometric economic model obtained is as follows (see formula 3):

$$
\begin{aligned}
Y_{\text {hunan }} & =e^{0.287} \times P_{-} F I^{0.079} \times P_{-} I^{0.427} \times P_{-} C I^{-0.032} \times P_{-} T I^{0.332} \times P_{-} F E_{-} T^{0.039} \\
& \times P_{-} F E_{-} I^{0.017} \times P_{-} E I^{-0.006} \times P_{-} F D I^{0.005} \times P_{-} T S M^{-0.111} \times P_{-} L B^{0.079}
\end{aligned}
$$

Note: variable $Y_{\text {hunan }}$ represents the regional GDP in Hunan, variable $P_{-} F I$ represents the proportion of added value of primary industry of Hunan in that of Central China; variable $P_{-} I I$ represents the proportion of added value of the secondary industry of Hunan in that of Central China, variable $P_{-} C I$ represents the proportion of added value of building industry of Hunan in that of Central China; variable $P_{-} T I$ represents the proportion of proportion of added value of the tertiary industry of Hunan in that of Central China; variable $P_{-} F E_{-} T$ represents the proportion of total asset of fixed asset of Hunan in that of Central China; variable $P_{-} F E_{-} I$ represents the proportion of total fixed asset investment of Hunan in that of Central China; variable $P_{-} E I$ represents the proportion of total export of Hunan in that of Central China; variable $P_{-} F D I$ represents the total amount of actual foreign capital of foreign direct investment of Hunan in that of Central China; variable $P_{-}$TSM represents the total international tourism income of Hunan in that of Central China; variable $P_{-} L B$ represents the proportion of total number of practitioners in Hunan in that of Central China and variable $e$ is an index function.

The main corresponding statistical indicators of this mode, R-squared and adjusted R-squared are respectively $0.996837,0.990512$. The econometric analysis requires that the two indicators should be both more than 095, and this is sufficient to explain that the model constructed in this research is significantly grounded from the perspective of statistics. It can be seen from the metering model expressed in formula 3 that from the perspective of the regional economic development, the agglomeration degrees with contribution to Hunan economy in a descending order are respectively: agglomeration degree of added value of the secondary industry, agglomeration degree of added value of the tertiary industry, fundamental (constant), agglomeration degree of number of practitioners, agglomeration degree of the primary industry, agglomeration degree of total amount of fixed asset; agglomeration degree of total fixed asset in the whole society, agglomeration degree of actual foreign capital use in foreign direct investment, agglomeration degree of added value of building industry, agglomeration degree of total export and agglomeration degree of international tourism income. In the above factors, the value of the later three are all less than zero, and other values are more than zero.

Through formula 3, we will have basic position of economic development in Hunan, but the main problem that we should solve is the selection of development direction of future economy of Hunan and its main industries, and further, it is which development road can rapidly improve the development of Hunan economy under the existing development model or frame. Aimed at this problem, we attempt to solve it through the mathematical analysis method. In the optimal analysis theory $^{\text {viviii }}$, there is a famous theory, steepest descent method theory. This theory is to solve the 
problem that which road selected can achieve the purpose of rapidest increasing or decreasing from the current point under the premise of giving a curve surface. It is specifically described as follows in mathematical language (formula 4):

$$
\begin{aligned}
& \max : \Delta f(x)_{t+1} \\
& \text { s.t. } \Delta f(x)_{t+1}=f(x)_{t+1}-f(x)_{t} \\
& \text { s.t. } f(x)=G(x), x \in[1, t]
\end{aligned}
$$

Note: variable $G(x)$ is a known curve surface, the form of which is fixed; variable $f(x)$ is an incompletely determined curve surface, the specific form of which has been determined before the time $t+1$ (not including $t+1$ ); variable $\Delta f(x)_{t+1}$ represents the amplification of the incompletely determined curve surface in $\Delta(t+1)$; symbol s.t. represents the condition met; and symbol max represents the maximum value.

In the optimal theory ${ }^{\text {ix }}$, through theoretical research, we have proven that the steepest rising path that can be realized is $\left(\frac{\partial f(x)}{\partial x_{1}}, \frac{\partial f(x)}{\partial x_{2}}, \cdots, \frac{\partial f(x)}{\partial x_{i}}, \cdots, \frac{\partial f(x)}{\partial x_{l}}, \frac{\partial f(x)}{\partial x_{l+1}}\right)$. Based on this theory, we use it in the front ${ }^{\mathrm{x}}$ optimal rising path of economic development in Hunan, thus obtaining the optimal path of economic development in Hunan, as follows (see formula 5 specifically):

$$
\text { Opti_dir }=\left(\frac{\partial Y_{\text {hunan }}}{\partial P_{-} F I}, \frac{\partial Y_{\text {hunan }}}{\partial P_{-} I I}, \frac{\partial Y_{\text {hunan }}}{\partial P_{-} C I}, \frac{\partial Y_{\text {hunan }}}{\partial P_{-} T I}, \frac{\partial Y_{\text {hunan }}}{\partial P_{-} F E_{-} T}, \frac{\partial Y_{\text {hunan }}}{\partial P_{-} F E_{-} I}, \frac{\partial Y_{h_{\text {hunan }}}}{\partial P_{-} E I}, \frac{\partial Y_{h_{\text {hunan }}}}{\partial P_{-} F D I}, \frac{\partial Y_{\text {hunan }}}{\partial P_{-} T S M}, \frac{\partial Y_{\text {hunan }}}{\partial P_{-} L B}\right)
$$

Note: variable Opti_dir represents the steepest development direction; variable $\frac{\partial Y_{\text {hunan }}}{\partial P_{-} F I}$ represents the marginal output of regional production relative to the added value of primary industry in that region, others are identical and are not repeated here.

Combining the marginal output in the micro economics with formula 5, we can obtain the expression of steepest development direction in economic development of Hunan, specifically as follows (see formula 6):

$$
\left\{\begin{array}{l}
\frac{\partial Y_{\text {hunan }}}{\partial P_{-} F I}=\frac{\alpha_{P_{-} F I}}{P_{-} F I} Y_{\text {hunan }} \\
\cdots \\
\frac{\partial Y_{\text {hunan }}}{\partial P_{-} F E_{-} I}=\frac{\alpha_{P_{-} F E_{-} I}}{P_{-} F E_{-} I} Y_{\text {hunan }} \\
\cdots \\
\frac{\partial Y_{\text {hunan }}}{\partial P_{-} L B}=\frac{\alpha_{P_{-} L B}}{P_{-} L B} Y_{\text {hunan }}
\end{array}\right\}
$$

Note: variable $\alpha_{P_{-} F I}$ represent the function coefficient of variable $P_{-} F I$ in formula 3; other variables are identical, and are not repeated here.

\section{Suggestions for construction of new pattern of economic development of Hunan}

The research on the industrial development of provincial economy in China is generally classified into two categories, one is the purely theoretical research, macro guiding opinions and suggestions are given to the provincial development; the other is modeling research, the econometric analysis method is separately used to give certain opinions and suggestions of empirical guidance to the industrial development of provincial economy. Both methods have their shortcomings, especially the latter, and the biggest shortcoming is that the defective analysis single in method, and it is very 
difficult to give a systematic solution for the empirical research. Aimed at this shortcoming, in this research, the systematic analysis method is used to research on how to develop economy and arrange industry most effectively for Hunan in Central China. Based on this idea, we have constructed the steepest development model from the perspective of steepest descent. Through the calculation of this model, we finally determine the steepest development direction of Hunan. This direction is a specific direction of complete quantification, thus solving the shortcomings of the previous researches of only limiting to the theoretical research and lack of specific guiding opinions and lack of quantitative guiding opinions.

\section{Acknowledgments}

This paper is: 1. Significant bid invitation project of the National Social Science Fund (12\&ZD003); 2. Key project of philosophy and social science fund in Hunan 13ZDB11); 3. Funding project of philosophy and social science fund of Hunan (12YBA281)

\section{References}

[1] Anna Trevisan, Massimo D'Isidoro and Olivier Talagrand.Four-dimensional variational assimilation in the unstable subspace and the optimal subspace dimension .Quarterly Journal of the Royal Meteorological Society,Volume 136,Issue 647, January 2010 Part B, Pages:487-496.

[2] Jin Yuguo, Latent Variable Model in Econometrics: A Survey from the Perspective of Methodology , Statistical Research, 2012(09):13-18.

[3] Zhang Yanqun, Theory, Method and Application of Global Vector Autoregression Model , Quantitative \& Technical economics, 2012(04):07-12.

[4] Pan Kangyu, Zhao Ying, Li Lijun, Research on Correlation between Talent Agglomeration and Regional Economic Development-Take Tianjin Binhai New District as an Example , Technoeconomics \& Management Research, 2012(10):17-22.

[5] Peter C. B. Phillips.Laws and Limits of Econometrics .The Economic Journal, Volume 113,Issue 486, March 2003, Pages: C26-C52.

[6] Liao Lei, Tang Yufeng, Empirical Research on Contribution of Human Capital to Economic Growth of Hunan , Economic Geography, 2012(01):15-19.

[7] Chi Guotai, Yang Zhongyuan, Optimization Model of Series Prospect Hedging based on Minimum Variance , System Engineering Theory and Practice, 2009(12):15-19.

[8] Gao Mingxia, He Guoguang, Comprehensive Optimization Model of Optimal Evacuation Path and Starting Time of Dynamic System , System Engineering, 2009(06):13-17

[9] Xinhai Liu, Shi Yu, Frizo Janssens, Wolfgang Glnzel, Yves Moreau and Bart De Moor .Weighted hybrid clustering by combining text mining and bibliometrics on a large-scale journal database .Journal of the American Society for Information Science and Technology, Volume 61, Issue 6, June 2010, Pages: 1105-1119.

[10]Tang Anjie, Route Selection of High-tech Service Industry Base of Chenzhou, Hunan Macroeconomic Management, 2012(06):09-13. 
